\title{
Teores de isoflavonas em grãos inteiros e nos componentes dos grãos de diferentes cultivares de soja (Glycine max (L.) Merrill)
}

\author{
Isoflavone contents of whole soybeans and their components, \\ obtained from different cultivars (Glycine max (L.) Merrill)
}

\section{Autores | Authors}

Carlos Eduardo da SILVA

Faculdade de Apucarana (FAP) Apucarana/PR - Brasil e-mail:cesilva7@gmail.com

$\bowtie$ Mercedes Concórdia CARRÃOPANIZZI

Embrapa Soja Rod. Carlos João Strass, Distrito de Warta Caixa Postal: 231 CEP: 86001-970 Londrina/PR - Brasil e-mail:mercedes@cnpso.embrapa.br

José Marcos Gontijo MANDARINO

Rodrigo Santos LEITE Embrapa Soja Londrina-PR, Brasil e-mail:jmarcos@cnpso.embrapa.br rsleite@cnpso.embrapa.br

\section{Ana Paula do Amaral MÔNACO}

Faculdade de Apucarana (FAP) Apucarana/PR - Brasil e-mail: anapaulamonaco@yahoo.com.br

$\triangle$ Autor Correspondente / Corresponding Author

Recebido / Received: 14/12/2010 Aprovado / Approved: 05/12/2011 Publicado / Published: jun./2012

\section{Resumo}

Devido à maior concentração de isoflavonas nos hipocótilos dos grãos de soja, a indústria de alimentos tem utilizado esse componente do grão como matéria-prima. No presente trabalho, foram quantificados os teores de isoflavonas nas estruturas formadoras do grão de soja (hipocótilo, cotilédones e casca), analisadas por Cromatografia Líquida de Alta Eficiência (CLAE). Foram avaliadas quatro cultivares de sojas especiais: BRS 184, BRS 216, BRS 257 e BRS 267, desenvolvidas pela Embrapa Soja. Todas as cultivares apresentaram maior teor de isoflavonas totais no hipocótilo (média de 2029,32 mg.100 g-1). No grão inteiro $\left(267,16 \mathrm{mg} 100 \mathrm{~g} \mathrm{~g}^{-1}\right.$ ) e nos cotilédones (209,16 mg.100 g-1), os teores de isoflavonas foram cerca de dez vezes menores do que nos hipocótilos. A cultivar BRS 216 apresentou o teor maior de isoflavonas totais no hipocótilo (2583,20 mg.100 g-1). Embora a casca da soja não apresente isoflavonas, observou-se que esses compostos estavam presentes nessa parte do grão numa quantidade média de $105,58 \mathrm{mg} .100 \mathrm{~g}^{-1}$, devido à presença de resíduos do hipocótilo e dos cotilédones provenientes do processo de descasque. Essa composição residual da casca favorece sua utilização como matéria-prima fonte de fibras, porque também fornece isoflavonas e outros compostos da soja.

Palavras-chave: Cultivares de soja especiais; Isoflavonas; Agliconas; CLAE.

\section{Summary}

Due to the higher concentration of isoflavones in the soybean hypocotyls, the food industry has used this component of the bean as a raw material. This paper reports the isoflavone contents found in the different parts of the bean (hypocotyl, cotyledon and hull) as analyzed by High Performance Liquid Chromatography (HPLC). Four special soybean cultivars, BRS 184, BRS 216, BRS 257 and BRS 267, developed by Embrapa Soybean, were evaluated. All the cultivars presented higher

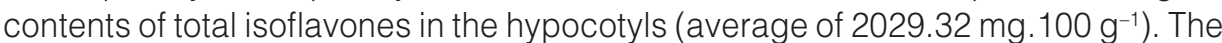
isoflavone contents of the whole beans (267.16 mg.100 g $\mathrm{g}^{-1}$ ) and the cotyledons (209.16 mg.100 g $\mathrm{g}^{-1}$ ) were about 10 times lower than that of the hypocotyls. Cultivar BRS 216 presented the highest total isoflavone content in the hypocotyl (2583.20 mg.100 g $\mathrm{g}^{-1}$ ). Although soybean hulls do not contain isoflavones, an average of $105.57 \mathrm{mg} .100 \mathrm{~g}^{-1}$ was found in this component, due to the presence of hypocotyl and cotyledon residues resulting from the hulling process. This residual composition of the hulls favors their use as a raw material that is a source of fibers, also providing isoflavones and other soybean compounds.

Key words: Special soybean cultivars; Isoflavones; Aglycones; HPLC. 
Teores de isoflavonas em grãos inteiros e nos componentes dos grãos de diferentes cultivares de soja (Glycine max (L.) Merrill)

SILVA, C.E. et al.

\section{Introdução}

O grão de soja possui diversos compostos funcionais, dentre os quais se destacam as isoflavonas, que são compostos fenólicos bioativos que podem reduzir os riscos de doenças cardiovasculares, de alguns tipos de câncer, de osteoporose e de diabetes (BARNES et al., 1999; MANDARINO, 2010; LAUDANNA, 2006). As isoflavonas também são conhecidas como fitomônios, porque possuem estrutura química semelhante à do estrógeno humano e podem auxiliar na redução dos sintomas do climatério (LAUDANNA, 2006).

Dentre todos os grãos já estudados, o grão de soja é o que possui os maiores teores de isoflavonas, as quais estão relacionadas a fatores genéticos e ambientais, como já demonstrado em um mapeamento do teor de isoflavonas em cultivares de soja realizado no Brasil. Nesse levantamento, os teores analisados variaram entre 12 e $461 \mathrm{mg} .100 \mathrm{~g}^{-1}$, confirmando a relação da formação de isoflavonas no grão de soja com efeitos genéticos e com o clima da região em que a soja foi cultivada (CARRÃO-PANIZZI et al., 2009a).

Os teores de isoflavonas na soja também variam conforme a parte morfológica da qual são extraídas (cotilédone, hipocótilo e casca). Estudos mostraram que a maior concentração de isoflavonas se encontra no hipocótilo, com valores de 10 a 20 vezes maiores do que nos grãos inteiros (TSUKAMOTO et al., 1995). Kudou et al. (1991) observaram que o hipocótilo apresenta cinco a seis vezes mais isoflavonas que os cotilédones, sendo que a glicitina e seus derivados somente ocorrem no hipocótilo (42,84\% do total de isoflavonas deveu-se à presença das formas glicitinas). Os mesmo autores também observaram que as isoflavonas não estão presentes na cascas dos grãos.

As isoflavonas compreendem as formas agliconas genisteína, gliciteína e daidzeína, que não possuem a molécula de glicose ligada à sua cadeia principal; as formas glicosiladas daidzina, glicitina e genistina, que possuem uma molécula de glicose ligada à cadeia principal, e seus derivados malonil e acetil (CARRÃOPANIZZI, 1996).

As isoflavonas são absorvidas nas formas agliconas, daidzeína, gliciteína e genisteína, enquanto que as formas glicosídicas precisam ser transformadas em agliconas no organismo para serem absorvidas (SETCHELL et al., 2001). O processo de fermentação favorece a conversão das demais formas de isoflavonas em agliconas (CARRÃO-PANIZZI et al., 2003; COWARD et al., 1998) e, portanto, estas são encontradas em maior concentração nos alimentos fermentados derivados da soja, como o "tempeh" e o "misô".

Além das propriedades funcionais das isoflavonas presentes na soja, outros compostos constituintes do grão (proteínas, ácidos graxos e minerais, entre outros) também favorecem sua utilização na alimentação humana. Em razão do alto teor de isoflavonas nos hipocótilos do grão de soja, tem sido comum a utilização dos hipocótilos no processamento de alimentos à base de soja. Este trabalho, portanto, teve como objetivo analisar o teor de isoflavonas nas diferentes partes dos grãos de soja provenientes de diferentes cultivares de soja, as quais foram melhoradas geneticamente por melhoramento tradicional para serem mais adequadas à utilização pela indústria de alimentos. A cultivar BRS 184 é uma cultivar convencional "tipo grão", enquanto que as cultivares BRS 216, BRS 257 e BRS 267 são cultivares especiais, desenvolvidas na Embrapa Soja para atender nichos de mercado visando à alimentação humana. A cultivar BRS 216 apresenta alto teor de proteína e sementes pequenas, adequada para produção de "natto" (alimento fermentado de origem japonesa) e "moyashi" (brotos de soja). A BRS 257 não apresenta as enzimas lipoxygenases, o que confere sabor melhor aos grãos dessa cultivar, e a BRS 267, que apresenta sementes grandes, hilo claro e melhor sabor, adequada para produção de "tofu" (queijo de soja) (CARRÃO-PANIZZI et al., 2009b).

\section{Material e métodos}

Foram utilizadas quatro cultivares de soja: BRS 184, BRS 216, BRS 257 e BRS 267 da safra 2008/2009, sendo que as BRS 184, BRS 257 e BRS 267 foram cultivadas em Londrina-PR (23 19' 22" S e 51 09' 07" O, altitude 569 m) e a BRS 216 foi cultivada em Mauá da Serra (2354' 16" S e 51' 13' 43" O, altitude 1020 m), no Estado do Paraná.

\subsection{Processamento dos grãos}

Os grãos das cultivares foram descascados em sistema mecânico numa máquina descascadora de soja modelo UBF - Unidade Beneficiadora de Soja da marca Embrasoy, na Embrapa Soja. Durante esse processo mecânico de descasque, as partes do grão são separadas em cotilédones, hipocótilo e casca. Para análise das cascas, um segundo lote de amostras de grãos inteiros também foi descascado manualmente. Para facilitar o descasque manual, as amostras foram liofilizadas em um liofilizador marca Liobrás, modelo Liotop L101 a $-55^{\circ} \mathrm{C}$ por 24 h. Com a liofilização, o grão seco se retrai e as cascas ficam menos aderentes, facilitando o descasque. Posteriormente, estas foram moídas em moinho refrigerado da marca Tecnal, modelo TE - 631/2 e mantidas em recipientes fechados e armazenadas em câmara fria $\left(15^{\circ} \mathrm{C}\right.$ e $45 \%$ de umidade), até o momento da realização das análises. Todas as amostras foram analisadas em base seca, cuja conversão foi realizada pelo cálculo da umidade das amostras (grãos inteiros, hipótilos, cotilédones e cascas), medida em balança analítica com aquecedor infravermelho (marca HAUS, 
Teores de isoflavonas em grãos inteiros e nos componentes dos grãos de diferentes cultivares de soja (Glycine max (L.) Merrill)

SILVA, C.E. et al.

modelo MB-45). A umidade calculada foi descontada dos resultados em base úmida.

\subsection{Extração e determinação de isoflavonas por CLAE}

A extração das isoflavonas foi realizada de acordo com a metodologia de Carrão-Panizzi et al. (2002), segundo a qual as amostras (sementes) foram trituradas em micromoinho analítico (marca Tecnal, modelo TE - 631/2) e desengordurdas com n-hexano, em temperatura ambiente, sob agitação constante por $8 \mathrm{~h}$. Posteriormente, $100 \mathrm{mg}$ de cada amostra triturada e desengordurada foram transferidos para tubos de ensaio de $10 \mathrm{~mL}$ com tampa rosqueável. Em seguida, foram adicionados $4,0 \mathrm{~mL}$ de solução de etanol $70 \%$, contendo $0,1 \%$ de ácido acético. Os tubos contendo as amostras e a solução extratora foram homogeneizados a cada $15 \mathrm{~min}$ por $1 \mathrm{~h}$ em agitador de tubos do tipo "Vortex" e submetidos à extração por uma hora em temperatura ambiente. Após a homogeneização e antes do sobrenadante ser transferido para os tubos de Eppendorf, os tubos foram ultrassonificados por $30 \mathrm{~min}$. Foram centrifugados em microcentrífuga do "tipo Eppendorff" (modelo 5417 R) por $15 \mathrm{~min}$, a $14.000 \mathrm{rpm}$, numa temperatura de $4{ }^{\circ} \mathrm{C}$, $1,5 \mathrm{~mL}$ do extrato. $\mathrm{O}$ sobrenadante foi filtrado através de membrana com poros de 0,45 $\mu \mathrm{m}$, da marca "Millipore". Para injeção no cromatográfo líquido, foram utilizados $20 \mu \mathrm{L}$ do extrato filtrado.

A separação e a quantificação das isoflavonas foram realizadas de acordo com modificações na metodologia preconizada por Berhow (2002), em cromatógrafo líquido da marca Waters, modelo 2690, com injetor automático de amostras. Utilizou-se, para tanto, uma coluna de fase reversa do tipo ODS C18 YMC-Pack ODS-AM, S-5 mm, 120 A com 250 mm de comprimento $\times 4,6 \mathrm{~mm}$ de diâmetro interno e partículas de $5 \mu \mathrm{m}$. Para a separação das isoflavonas, adotou-se o sistema de gradiente linear binário, tendo-se como fases móveis: 1) metanol contendo 0,025\% ácido trifluoroacético (TFA) (solvente A) e 2) água destilada deionizada ultrapura contendo $0,025 \%$ de TFA (solvente B). A condição inicial do gradiente foi de $20 \%$ para o solvente $A$, que, aos 40 minutos, atingiu a concentração de $100 \%$ para, em seguida, retornar a $20 \%$ aos 41 min e permanecer nessas condições até os 60 min. Portanto, o tempo total de corrida para cada amostra foi de 60 min. A vazão da fase móvel foi de $1,0 \mathrm{~mL} \cdot \mathrm{min}^{-1} \mathrm{e}$ a temperatura de $25^{\circ} \mathrm{C}$ da coluna foi mantida constante durante toda a corrida. Para a detecção das isoflavonas, foi utilizado o detector de arranjo de foto diodo da marca Waters, modelo 996, ajustado para o comprimento de onda igual a $254 \mathrm{~nm}$. Para a identificação dos picos correspondentes a cada uma das isoflavonas, foram utilizados padrões para as 12 formas das isoflavonas (glucosídeos, acetis, malonils e agliconas) da marca Sigma, solubilizados em metanol (grau HPLC), nas seguintes concentrações: 0,00625; 0,$0125 ; 0,0250 ; 0,0500$ e 0,1000 mg.mL $\mathrm{mL}^{-1}$, a partir das quais se construíram as curvas padrões para cada forma. Essas concentrações foram utilizadas após obterem-se o LQ e o LD do equipamento com padrões de daidzeína e genisteína. O limite de detecção (LD) foi 0,0005 mg. $\mathrm{mL}^{-1}$ e o limite de quantificação (LQ) foi $0,0015 \mathrm{mg} \cdot \mathrm{mL}^{-1}$. Para a quantificação das 12 formas de isoflavonas, por padronização externa (área dos picos), foram utilizadas as curvas padrões como referência. Os tempos de retenção identificados dos padrões para cada grupo de isoflavonas foram para os glicosil conjugados: daidzina $=19,75 \mathrm{~min}$, glicitina $=20,40 \mathrm{~min}$ e genistina $=22,75 \mathrm{~min}$; para as formas malonil: $\mathrm{m}$-daidzina $=24,60 \mathrm{~min}$, m-glicitina $=25,20$ min e m-genistina $=27 \mathrm{~min}$; para as formas acetil: ac-daizina $=26 \mathrm{~min}$, ac-glicitina $=26,60 \mathrm{~min}$ e ac-genistina $=28,80 \mathrm{~min}$; e para as agliconas: daizeína $=29,00 \mathrm{~min}$, gliciteína $=29,50 \mathrm{~min}$ e genisteína $=31,60 \mathrm{~min}$.

Os teores de isoflavonas determinados foram expressos em mg.100 $\mathrm{g}^{-1}$ de amostra em base seca. As isoflavonas separadas e quantificadas foram os $\beta$-glicosídeos conjugados (daidzina, glicitina e genistina), os derivados malonil- $\beta$-glicosídeos (malonildaidzina, malonilglicitina e malonilgenistina) e as agliconas (daidzeína, gliciteína e genisteína). As formas acetil não foram identificadas porque não ocorrem no grão in natura, pois se formam após tratamento térmico dos grãos (COWARD et al., 1998). Os valores de isoflavonas podem ser apresentados em equivalentes agliconas (GÓES-FAVONI et al., 2010) ou podem ser apresentados como a somatória das diferentes formas (YUE et al., 2010; TSUKAMOTO et al., 1995). Neste trabalho, os dados apresentados são as somatórias dos valores dos compostos determinados para cada grupo de isoflavonas (glicosídeos, malonils e agliconas).

\subsection{Análises estatísticas}

O delineamento estatístico foi inteiramente casualizado, num arranjo fatorial (4 cultivares e 4 tratamentos de grãos) com três repetições. Os dados foram submetidos à análise de variância (ANOVA) e as médias foram comparadas pelo teste de Tukey a $5 \%$ de probabilidade (TUKEY, 1949). Os programas SAS-Statistical Analysis Sistema (SAS, 2001) e Sanest (ZONTA et al., 1982) foram utilizados.

\section{Resultados e discussão}

O teor de umidade dos grãos das cultivares estudadas foi semelhante, sendo que, nas diferentes partes, em média, a umidade foi de $7,39 \%$ nos grãos inteiros, $7,04 \%$ no hipocótilo e $7,19 \%$ nos cotilédones. A 
Teores de isoflavonas em grãos inteiros e nos componentes dos grãos de diferentes cultivares de soja (Glycine max (L.) Merrill)

SILVA, C.E. et al.

casca, possivelmente por ser o componente mais externo do grão, apresentou maior teor de umidade (9,94\%).

\subsection{Total de isoflavonas}

Com relação ao total, ou seja, a somatória de todas as formas de isoflavonas identificadas no grão inteiro (Tabela 1), as cultivares BRS 184 e BRS 257 apresentaram maior concentração de isoflavonas (336,66 e 294,43 mg. $100 \mathrm{~g}^{-1}$, respectivamente). A cultivar BRS 267 apresentou o menor teor $\left(165,26 \mathrm{mg} 100 \mathrm{~g}^{-1}\right)$.

No hipocótilo, como já observado por Kudou et al. (1991) e Tsukamoto et al. (1995), ocorrem as maiores concentrações de isoflavonas, o que, em alguns casos, leva as indústrias processadoras de alimentos à base de soja utilizarem o hipocótilo como matéria-prima. Entre as cultivares estudadas, o maior teor de isoflavonas no hipocótilo, que representa $2 \%$ do grão, foi observado na cultivar BRS 216 (2583,20 mg.100 g $\left.{ }^{-1}\right)$ e o menor foi observado na cultivar BRS 267 (1780,48 mg.100 g ${ }^{-1}$ ).

Nos cotilédones, que constituem $90 \%$ do grão de soja, os teores de isoflavonas nas cultivares foram semelhantes aos observados no grão inteiro, sendo que as cultivares BRS 184 (288,76 mg.100 g $\left.\mathrm{g}^{-1}\right)$ e BRS 257 (255,07 mg.100 $\mathrm{g}^{-1}$ ) apresentaram os maiores teores de isoflavonas, e a BRS 267, o menor teor (Tabela 1). Conforme observado por Kudou et al. (1991) e Tsukamoto et al. (1995), na casca, que representa 8\% do grão, não deveria haver isoflavonas. Entretanto, em razão de o sistema mecânico de descasque dos grãos não ser tão eficiente quando comparado à separação manual das partes dos grãos, as cascas não ficam completamente limpas e apresentam porções residuais de cotilédones e de hipocótilos. Para confirmar as observações de Kudou et al. (1991) e Tsukamoto et al. (1995), procedeu-se o descasque manual dos grãos das cultivares e as amostras de cascas foram analisadas novamente. Não se observou a presença de isoflavonas nas cascas provenientes do descasque manual dos grãos de todas as cultivares analisadas.

Convém salientar que o descasque mecânico, que viabiliza a separação dos hipocótilos, predispondo à certa contaminação das cascas com porções dos mesmos, não se constitui em um problema, mas sim em uma vantagem, principalmente quando essas cascas com porções de hipocótilos deverão ser utilizadas como fonte de fibras e de isoflavonas.

A BRS 267 apresentou o menor teor de isoflavonas no grão inteiro e nos cotilédones; porém, essa cultivar apresentou o maior teor de isoflavonas na casca com 144,46 mg. $100 \mathrm{~g}^{-1}$, apesar de não diferir estatisticamente da BRS $184 \mathrm{com} \mathrm{112,22} \mathrm{mg.100} \mathrm{g}{ }^{-1}$ e da BRS 257 com 102,33 mg. $100 \mathrm{~g}^{-1}$ (Tabela 1). A BRS 267 é uma cultivar com sementes grandes, cuja característica pode favorecer a quebra de cotilédones durante o descasque mecânico, fazendo com que as cascas apresentem maiores teores de resíduos.

A BRS 216 foi a cultivar que apresentou em seu hipocótilo maior teor de isoflavonas (2583,20 mg.100 g-1) e o menor teor de isoflavonas na casca $\left(68,71 \mathrm{mg} 100 \mathrm{~g}^{-1}\right)$ (Tabela 1). Essa cultivar apresenta sementes pequenas (peso de 100 sementes = $10 \mathrm{~g}$ ), característica que pode conferir certa resistência à quebra no processo de descasque mecânico, implicando menor contaminação de hipocótilos e cotilédones nas cascas.

$\mathrm{Na}$ cultivar BRS 216, o teor de isoflavonas nos cotilédones foi $65 \%$ menor $\left(117,18 \mathrm{mg} .100 \mathrm{~g} \mathrm{~g}^{-1}\right)$ que o teor observado no grão inteiro (272,38 mg. $\left.100 \mathrm{~g}^{-1}\right)$, o que pode ser decorrente do alto teor de isoflavonas observado no hipocótilo dessa cultivar, cujo teor foi $28 \%$ maior do que a média observada nas outras três cultivares; consequentemente, o alto teor de isoflavonas observado no hipocótilo acaba interferindo no teor de isoflavonas do grão inteiro (Tabela 1).

Entre as cultivares analisadas, a BRS 216 apresentou o maior teor de isoflavonas nos hipocótilos e, portanto, essa cultivar se constitui em excelente matéria-prima para a obtenção de produtos especiais enriquecidos com isoflavonas.

Conforme já observado por Kudou et al. (1991), os resultados deste trabalho também mostraram diferenças nos teores das isoflavonas segundo as diferentes partes dos grãos. Na Figura 1, estão apresentados os valores médios de todas as cultivares testadas para as concentrações das isoflavonas nas partes dos grãos.

Tabela 1. Teor de isoflavonas contidas em cada um dos componentes dos grãos nas quatro cultivares de soja analisadas e submetidas ao descasque mecânico (cv = 4,831\%, $n=80$ ).

\begin{tabular}{|c|c|c|c|c|}
\hline \multirow{2}{*}{ Cultivares } & \multirow{2}{*}{$\begin{array}{l}\text { Grão inteiro } \\
\left(\mathrm{mg} .100 \mathrm{~g}^{-1}\right)\end{array}$} & \multicolumn{3}{|c|}{ Componentes do grão (mg.100 g $\left.\mathrm{g}^{-1}\right)$} \\
\hline & & Hipocótilo & Cotilédones & Casca \\
\hline BRS 184 & $336,66^{\mathrm{Ba}}$ & $1887,84^{\mathrm{Ab}}$ & $288,76^{\mathrm{Ba}}$ & $112,22^{\mathrm{Cab}}$ \\
\hline BRS 216 & $272,38^{\mathrm{Bb}}$ & $2583,20^{\mathrm{Aa}}$ & $177,18^{\mathrm{Cb}}$ & $68,71^{\mathrm{Db}}$ \\
\hline BRS 257 & $294,34^{\mathrm{Bab}}$ & $1865,75^{\mathrm{Ab}}$ & $255,07^{\mathrm{Ba}}$ & $102,33^{\mathrm{Cab}}$ \\
\hline BRS 267 & $165,26^{\mathrm{Bc}}$ & $1780,48^{\mathrm{AC}}$ & $115,64^{\mathrm{Bc}}$ & $144,46^{\mathrm{Ba}}$ \\
\hline Média & $267,16^{\mathrm{B}}$ & $2029,32^{A}$ & $209,16^{c}$ & $106,9^{\mathrm{D}}$ \\
\hline
\end{tabular}

Médias seguidas pelas mesmas letras maiúsculas nas linhas e minúsculas nas colunas não diferem entre si pelo teste de Tukey $(p \leq 0,05)$. 
Teores de isoflavonas em grãos inteiros e nos componentes dos grãos de diferentes cultivares de soja (Glycine max (L.) Merrill)

SILVA, C.E. et al.

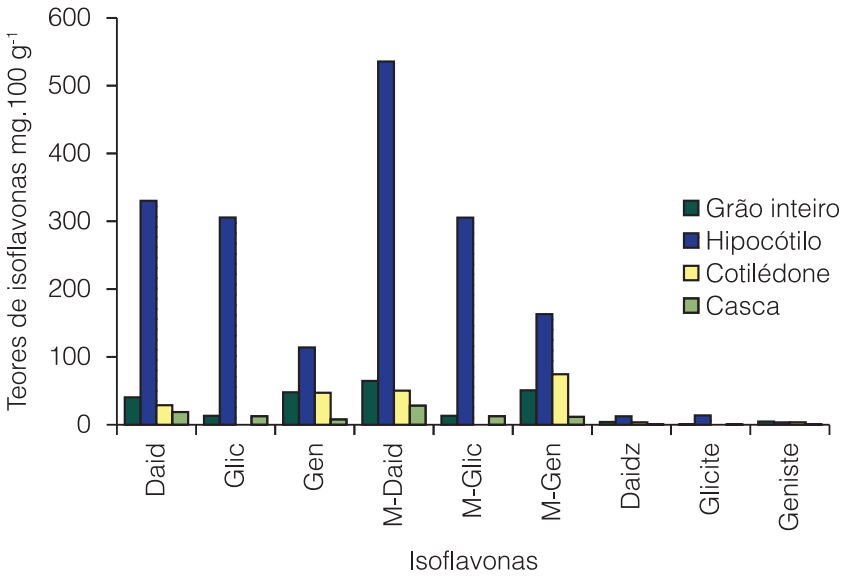

Figura 1. Valores médios dos teores de isoflavonas (mg.100 $\left.\mathrm{g}^{-1}\right)$ em diferentes partes do grão de soja (grão inteiro, hipocótilo, cotilédone e casca). (Daid = Daidzina, Glic = Glicitina, Gen = Genistina, M-Daid = Malonil Daidzina, M-Glic = Malonil Glicitina, M-Gen = Malonil Genistina, Daidz = Daidzeína, Glicite = Gliciteína, Geniste = Ginesteína .

Quando comparado com os outros componentes dos grãos, o hipocótilo apresentou maior concentração de isoflavonas, sendo que a glicitina só aparece no hipocótilo. Nas cascas, a concentração de isoflavonas que se observa se deve à mistura dos resíduos de outras partes do grão.

\subsection{Total de isoflavona glicosiladas}

Todas as cultivares apresentaram teores de isoflavonas glicosiladas (somatória dos teores das formas glicosil e malonil) significativamente iguais para os cotilédones e para o grão inteiro, exceto a cultivar BRS 216, que apresentou 267,14 mg.100 $\mathrm{g}^{-1}$ no grão inteiro e 173,60 mg.100 g ${ }^{-1}$ nos cotilédones. Os teores de isoflavonas glicosiladas (Tabela 2) seguiram a mesma tendência observada para o total de isoflavonas (Tabela 1), porque as formas malonil são encontradas em maiores quantidades no grão de soja (KUDOU et al., 1991). Os teores de isoflavonas glicosiladas encontrados nas cascas, nesta análise são provenientes dos resíduos do processo de descasque mecânico, pois foi observado um teor médio de 105,58 mg.100 $\mathrm{g}^{-1}$ de isoflavonas glicosiladas nas cascas, que é uma quantidade significativa quando se sabe que essas isoflavonas não ocorrem nas cascas.

\subsection{Total de isoflavonas agliconas}

As formas de isoflavonas glicosiladas que possuem uma molécula de glicose em sua cadeia e que são encontradas na maior parte dos alimentos à base de soja não são prontamente biodisponíveis. Durante a digestão dos alimentos ou pelo processo de fermentação, os glicosídeos são hidrolisados pela ação das enzimas $\beta$-glicosidases, formando as isoflavonas agliconas, que são as formas com maior biodisponibilidade (CASSIDY et al., 2006; COWARD et al., 1998). Dependendo da atividade da bactéria que coloniza o intestino humano, essas agliconas podem ser assimiladas ou podem ser metabolizadas em equol, composto biologicamente ativo (ROWLAND et al., 2003).

Tem sido observado que as isoflavonas agliconas estão ausentes ou em teores muito reduzidos nos grãos inteiros de soja provenientes de colheitas recentes (CARRÃO-PANIZZI et al., 2004). Presume-se, portanto, que se houver algum dano nos grãos de soja e se houver umidade, tem-se condições propícias para formação de agliconas pela ação das enzimas. Entretanto, nos grãos in natura, as agliconas estarão sempre em quantidades reduzidas.

As cultivares BRS 184 e BRS 257 apresentaram maior concentração de isoflavonas agliconas no grão inteiro (Tabela 3), conforme também foi observado para as isoflavonas totais e para as formas glicosiladas. A BRS 216, no entanto, apresentou o menor teor de agliconas $\left(4,64 \mathrm{mg} .100 \mathrm{~g}^{-1}\right)$. O tamanho pequeno dos grãos (peso de 100 sementes igual a $10 \mathrm{~g}$ ) da cultivar BRS 216 pode conferir maior resistência ao grão, reduzindo quebras e exposição à umidade, o que condicionaria a formação de isoflavonas agliconas, pois a umidade ativa as enzimas $\beta$-glicosidases (CARRÃO-PANIZZI et al., 2003). Apesar de a cultivar BRS 267 ter apresentado menores teores de isoflavonas totais e glicosiladas no hipocótilo (Tabelas 1

Tabela 2. Teor de isoflavonas glicosiladas contidas em cada um dos componentes dos grãos das quatro cultivares de soja analisadas e submetidas ao descasque mecânico (cv = 4,879\%, $n=80$ ).

\begin{tabular}{|c|c|c|c|c|}
\hline \multirow{2}{*}{ Cultivares } & \multirow{2}{*}{$\begin{array}{l}\text { Grão inteiro } \\
\left(\mathrm{mg} .100 \mathrm{~g}^{-1}\right)\end{array}$} & \multicolumn{3}{|c|}{ Componentes do grão (mg.100 g $\left.{ }^{-1}\right)$} \\
\hline & & Hipocótilo & Cotilédones & Casca \\
\hline BRS 184 & $323,78^{\mathrm{Ba}}$ & $1858,79^{\mathrm{Ab}}$ & $276,57^{\mathrm{Ba}}$ & $111,26^{\mathrm{Cab}}$ \\
\hline BRS 216 & $267,74^{\mathrm{Bb}}$ & $2556,18^{\mathrm{Aa}}$ & $173,60^{\mathrm{Cb}}$ & $67,92^{\mathrm{Db}}$ \\
\hline BRS 257 & $283,32^{\mathrm{Bab}}$ & $1836,92^{\mathrm{Ab}}$ & $246,66^{\mathrm{Ba}}$ & $101,00^{\mathrm{Cab}}$ \\
\hline BRS 267 & $157,04^{\mathrm{Bc}}$ & $1746,62^{\mathrm{Ac}}$ & $110,98^{\mathrm{BC}}$ & $142,45^{\mathrm{Ba}}$ \\
\hline Média & $257,97^{\mathrm{B}}$ & $1999,63^{A}$ & $201,95^{C}$ & $105,58^{\mathrm{D}}$ \\
\hline
\end{tabular}

Médias seguidas pelas mesmas letras maiúsculas nas linhas e minúsculas nas colunas não diferem entre si pelo teste de Tukey $(p \leq 0,05)$. 
Teores de isoflavonas em grãos inteiros e nos componentes dos grãos de diferentes cultivares de soja (Glycine max (L.) Merrill)

SILVA, C.E. et al.

Tabela 3. Teor de isoflavonas agliconas contidas em cada um dos componentes do grão das quatro cultivares de soja analisadas e submetidas ao descasque mecânico (cv $=14,749 \%, n=80)$.

\begin{tabular}{|c|c|c|c|c|}
\hline \multirow{2}{*}{ Cultivares } & \multirow{2}{*}{$\begin{array}{l}\text { Grão inteiro } \\
\left(\mathrm{mg} .100 \mathrm{~g}^{-1}\right)\end{array}$} & \multicolumn{3}{|c|}{ Componentes do grão (mg.100 g $\left.{ }^{-1}\right)$} \\
\hline & & Hipocótilo & Cotilédones & Casca \\
\hline BRS 184 & $12,88^{\mathrm{Ba}}$ & $29,05^{\mathrm{Ab}}$ & $12,18^{\mathrm{Ba}}$ & $0,96^{\mathrm{Ca}}$ \\
\hline BRS 216 & $4,64^{\mathrm{Bc}}$ & $27,01^{\mathrm{Ab}}$ & $3,58^{\mathrm{BCc}}$ & $0,79 \mathrm{Ca}$ \\
\hline BRS 257 & $11,01^{\mathrm{Bab}}$ & $28,82^{\mathrm{Ab}}$ & $8,41^{\mathrm{Bb}}$ & $1,33^{\mathrm{Ca}}$ \\
\hline BRS 267 & $8,22^{\mathrm{Bb}}$ & $33,85^{\mathrm{Aa}}$ & $4,66^{\mathrm{Cc}}$ & $2,31^{\mathrm{Ca}}$ \\
\hline Média & $9,19^{\mathrm{B}}$ & $29,68^{A}$ & $7,21^{\mathrm{C}}$ & $1,35^{\mathrm{D}}$ \\
\hline
\end{tabular}

Médias seguidas pelas mesmas letras maiúsculas nas linhas e minúsculas nas colunas não diferem entre si pelo teste de Tukey $(p \leq 0,05)$.

e 2), a mesma apresentou o maior teor de isoflavonas agliconas (33,85 mg. $\left.100 \mathrm{~g}^{-1}\right)$ nesse componente do grão. O teor de isoflavonas agliconas na casca foi reduzido, não havendo diferença significativa entre as cultivares.

Em razão da maior concentração de isoflavonas nos hipocótilos dos grãos de soja, estes têm sido muito utilizados pela indústria de alimentos à base de soja. O descasque mecânico é mais rápido e eficaz para a separação das partes dos grãos de soja para atender à demanda de uma indústria alimentícia. Entretanto, embora não tenha sido feito um estudo específico sobre o processo de descascamento, tem-se percebido (avaliação visual) que no descasque mecânico ocorre misturas de resíduos de diferentes partes dos grãos. O processo de separação manual, que deixaria cada parte do grão completamente limpa da interferência de resíduos não é eficaz para atender à demanda de grandes quantidades de matéria-prima. Portanto, mesmo que haja resíduos de outras partes dos grãos ou perdas de matériaprima, o descasque mecânico ainda é a melhor opção para a separação dos componentes dos grãos de soja.

Os resultados deste trabalho mostram que, apesar de haver certa contaminação entre as partes dos grãos em função do processo de descasque, os teores de isoflavonas são diferenciados e são maiores nos hipocótilos, sejam das formas agliconas ou glicosiladas. Essa características confirma a atenção que essa parte do grão tem merecido das indústrias de alimentos funcionais. Com relação ao teor de isoflavonas, a escolha da matériaprima é um fator importante, principalmente quando existe variabilidade entre as cultivares de soja para os teores de isoflavonas (CARRÃO-PANIZZI et al., 2009a). Convém considerar que, dependendo do local de cultivo da soja, os teores de isoflavonas podem aumentar, já que são favorecidos por temperaturas reduzidas durante o enchimento dos grãos (CARRÃO-PANIZZI et al., 1999). Os grãos de soja podem também ser submetidos a diferentes processos, como, por exemplo, fermentação, que favorecem a formação de isoflavonas agliconas, disponibilizando, assim, alimentos de maior valor nutritivo.

O descasque mecânico, que deixa resíduos de outras partes dos grãos (hipocótilo e cotilédones), favorece a composição das cascas em relação às isoflavonas existentes nessas partes. Nesse caso, a casca, além de ser fonte de fibras, também fornecerá isoflavonas e outros compostos nutricionais (proteínas, lipídios e minerais), que irão enriquecer essa matériaprima.

\section{Conclusão}

- Em razão dos resíduos de outras partes do grão (hipocótilo e cotilédones), o descasque mecânico permite que as cascas de soja, que se caracterizam por não apresentar isoflavonas, se constituam em fontes de proteínas, minerais e de isoflavonas, além das fibras;

- A cultivar BRS 216, que apresentou maior teor de isoflavonas no hipocótilo, entre as cultivares testadas, pode ser uma fonte desses compostos para produtos alimentares que veiculassem a soja como ingrediente.

\section{Agradecimentos}

À Embrapa Soja, pela Bolsa e pela oportunidade de estágio para o aluno Carlos Eduardo da Silva. Este artigo foi aprovado para publicação pelo Comitê de Publicações da Embrapa Soja sob o número 20/2010 ("This paper was aproved for publication by Editorial Board of Embrapa Soja as manuscript number 20/2010").

\section{Referências}

BARNES, S.; KIM, H.; XU, J. Soy in the prevention and treatament of chronic diseases. In: CONGRESSO BRASILEIRO DE SOJA, 1999, Londrina. Anais... Londrina: Embrapa CNPSo, 1999, p. 295-310. (Embrapa CNPSo. Documentos, n. 124).

BERHOW, M. A. Modern analytical techniques for flavonoid determination. In: BUSLING, B. S.; MANTHEY, J. A. (Eds.). Flavonids in the Living Cell. New York: Klusher Academic, 2002. p. 61-76. (Advances in Experimental Medicine and Biology, v. 505). 
Teores de isoflavonas em grãos inteiros e nos componentes dos grãos de diferentes cultivares de soja (Glycine max (L.) Merrill)

SILVA, C.E. et al.

CARRÃO-PANIZZI, M. C. Avaliação de cultivares de soja quanto aos teores de isoflavonóides. Pesquisa Agropecuária Brasileira, Brasília, v. 31, n. 10, p. 691-698, 1996

CARRÃO-PANIZZI, M. C.; BELÉIA, A. D. P.; KITAMURA, K.; OLIVEIRA, M. C. N. Effects of genetics and environment on isoflavone content fo soybean from different regions of Brazil.

Pesquisa Agropecuária Brasileira, Brasília, v. 34, n. 10, p. $1788-1795,1999$

CARRÃO-PANIZZI, M. C.; BERHOW, M.; MANDARINO, J. M. G.; OLIVEIRA, M. C. N. Enviromental and genetic variation of isoflavones content of soybean seeds grown in Brazil. Pesquisa Agropecuária Brasileira, Brasília, v. 44, n. 11, p. 1444-1451, 2009a.

CARRÃO-PANIZZI, M. C.; FAVONI, S. P. G.; KIKUCHI, A. Extraction time for isoflavone determination. Brazilian Archives of Biology and Technology, Curitiba, v. 45, n. 4, p. 515-518, 2002. http://dx.doi.org/10.1590/S1516-89132002000600015

CARRÃO-PANIZZI, M. C.; GOÉS-FAVONI, S. P.; KIKUCHI, A. Hydrothermal treatments in the development of isoflavone aglycones in soybean (Glycine $\max ($ L.) Merrill) grains. Brazilian Archives of Biology and Technology, Curitiba, v. 47, n. 2, p. 225-232, 2004. http://dx.doi.org/10.1590/S151689132004000200010

CARRÃO PANIZZI, M. C.; PÍPOLO, A. E.; MANDARINO, J. M. G.; ARANTES, N. E.; GARCIA, A.; BENASSI, V. T.; ARIAS, C. A.; KASTER, M.; OLIVEIRA, M. F.; OLIVEIRA, M. A.; TOLEDO, J. F. F.; MOREIRA, J. U. V.; CARNEIRO, G. E. S. Breeding specialty soybean cultivars for processing and value-added utilization at Embrapa in Brazil. In: WORLD SOYBEAN RESEARCH CONFERENCE - WSRC, 8., 2009, Beijing. Developing a global soy blueprint for a safe secure and sustainable supply: proceedings. Beijing. Proceedings... Beijing: Chinese Academy of Agricultural Sciences: Institute of Crop Science, 2009b. CD-ROM.

CARRÃO-PANIZZI, M. C.; SIMÃO, A. S.; KIKUCHI, A. Efeitos de genótipos, ambientes e de tratamentos hidrotérmicos na concentração de isoflavonas agliconas em grãos de soja. Pesquisa Agropecuária Brasileira, Brasília, v. 38, n. 8 , p. 897-902, 2003.

CASSIDY, A.; BROWN, J. E.; HAWDON, A.; FAUGHNAN, M. S.; KING, L. J.; MILWARD, J.; ZIMMER-NECHEMIAS, L.; WOFE, B.; SETCHELL, K. D. R. Factors affecting the biovailability of soy isoflavones in humans after ingestion of physiologically relevant levels from different soy foods. Journal of Nutrition, Bethesda, v. 136, n. 1, p. 45-51, 2006.

COWARD, L.; SMITH, M.; KIRK, M.; BARNES, S. Chemical modification of isoflavones in soyfoods during cooking and processing. Journal of Clinical Nutrition, Bethesda,v. 68, p. 1486S-91S, 1998.

GÓES-FAVONI, S. P.; CARRÃO-PANIZZI, M. C.; BELÉIA, A. D. P. Changes of isoflavone in soybean cotyledons soaked in different volumes of water. Food Chemistry, Oxford, v. 119, p. 1605-1612, 2010. http://dx.doi.org/10.1016/j.foodchem.2009.09.051

KUDOU, S.; FLEURY, Y.; WELTI, D.; MAGNOLATO, D.; UCHIDA, T.; KITAMURA, K.; OKUBO, K. Malonyl isoflavone glycosides in soybean seeds (Glycine maxMerrill). Agricultural and Biological Chemistry, Japão, v. 55, n. 9, p. 2227-2233, 1991. http://dx.doi.org/10.1271/bbb1961.55.2227

LAUDANNA, E. Propriedades funcionais da soja. Informe Agropecuário, Belo Horizonte, v. 27, n. 230, p. 15-18, 2006

MANDARINO, J. M. G. Compostos Antinutricionais da Soja: Caracterização e Propriedades Funcionais. In: COSTA, N. M. B.; ROSA, C. O. B. Alimentos funcionais: componentes bioativos e efeitos. Rio de Janeiro: Rubio, 2010. p. 177-192.

ROWLAND, M.; FAUGHNAN, L.; HOEY, K. WAHALA, G.; WILLIAMSON, G.; CASSIDY, A. Bioavailability of phytooestrogens. British Journal of Nutrition, Cambridge, v. 89, p. S45-S58, 2003. Supplement 1. http://dx.doi.org/10.1079/ BJN2002796

SETCHELL, K. D. R.; BROWN, N. M.; DESAI, P.; ZIMMERNECHEMIAS, L.; WOLFE, B. E.; BRASHEAR, W. T.; KIRSCHNER, A. S.; CASSIDY, A.; HEUBI, J. E. Bioavailability of pure isoflavones in healthy humans and analysis of commercial soy isoflavone supplements. Journal of Nutrition, v. 131, p. 1362S1375S, 2001

\section{STATISTICAL ANALISYS SYSTEM INSTITUTE - SAS. SAS User's} Guide: Statistics. version 8.2. Cary: SAS Institute, 2001.

TSUKAMOTO, C.; SHIMADA, S.; IGITA, K.; KUDOU, S.; KOKUBUN, M.; OKUBO, K.; KITAMURA, K. Factors Affecting Isoflavone Content in Soybean Seeds: Changes in Isoflavones, Saponins, and Composition of Fatty Acids at Different Temperatures during Seed Development. Journal of Agricultural and Food Chemistry, Washington, v. 43, n. 5, p. 1184-1192, 1995. http://dx.doi.org/10.1021/jf00053a012

TUKEY, J. W. One degree of freedom for non-additivity. Biometrics, Alexandria, v. 5, p. 232-242, 1949. http://dx.doi. org/10.2307/3001938

YUE, X.; MOURSY, A.; XU, Z. Distribution of isoflavones and antioxidant activities of soybean cotyledon, coat and germ. Journal of Food Preservation, Malden, v. 34, n. 5, p. 795-806, 2010. http://dx.doi.org/10.1111/j.1745-4549.2009.00395.x

ZONTA, E. P.; MACHADO, A. A.; SIIVEIRA JÚNIOR, P. Sistema de Análise Estatística. Pelotas: UFPEL, 1982. 63 p. 